\title{
Effects of computer conferencing on the language use of emotionally disturbed adolescents
}

\author{
D. PATRICK ZIMMERMAN \\ University of Chicago, Chicago, Illinois
}

\begin{abstract}
This study compared the computer-mediated communications among 18 severely disturbed adolescents with their small-group, face-to-face discussions. A content analysis was performed to explore psychological, interpersonal, and expressive differences between the two communication modes. The findings indicated that computer involvement tended to improve communication in these areas.
\end{abstract}

A number of observers have concluded that the computer revolution may ultimately be responsible for more significant social, psychological, and educational effects upon the lives of many children and adolescents than almost any other technological advance during the past century (Deken, 1982; Evans, 1979; Lepper, 1982; Turkle, 1984; Vallee, 1982). There remains, however, strong disagreement about the nature of these effects. Enthusiasts of the new technology have claimed that computer use by youth will lead to increased motivation to learn, easier and earlier access to certain powerful ideas, a greater sense of self-esteem, and an increased feeling of independence (Lepper, 1982; Papert, 1980). On the other hand, critics warn that extensive use of computers poses a threat to human creativity, natural language, and "culture" as we know it. Furthermore, they fear that computer involvement may cause some youths to become emotionally constricted, socially isolated, impulsive, and sociopathic (Davy, 1984; Simpson, 1984; Sardello, 1984).

The attraction computer technology holds for children and adolescents has been widely recognized. Turkle (1984) recently proposed a number of psychological interpretations about differing user-machine interactions, largely based on her ongoing observations of children and adolescents involved with computerized toys, video games, and computer programming activities. Nevertheless, until now most empirical research has focused on the "instrumental" influences of computers upon youth in the specialized area of computer-assisted instruction (e.g., in terms of educational gains, learning retention, on-task behaviors, and the advantages of various system characteristics). Attempts to empirically study the broader issues of social influence or psychological effects of computer use have until now been largely neglected.

Although computer-mediated communication has been described as one of the more powerful aspects of computer technology (Vallee, 1982), a review of the current literature reveals no reference to its impact on adolescents.

The author's address is: The Sonia Shankman Orthogenic School, University of Chicago, 1365 East 60th St., Chicago, IL 60637.
It follows that until now little use has been made of computer technology either as a tool to further understand how adolescents communicate with and relate to each other or as a medium for possible use in the clinical treatment of disturbed adolescents.

Previous studies on the use of electronic communication by adults have focused largely upon structural issues such as the emergence of group leadership, equality of member participation, achievement of group consensus, quality of communication, and the degree of social influence. Equality of participation has frequently been cited as a major benefit of computer-mediated communication (Hiltz \& Turoff, 1978; Lipinski et al., 1979; Rice, 1980). In terms of group structure, Strickland, Guild, Barefoot, and Paterson (1978) compared face-to-face communication with audiovisual-based communication and observed that the hierarchical structure characteristic of face-to-face groups was absent in the audiovisual groups.

Studies of electronic conferencing have also found that the amount of time needed to achieve consensus is noticeably longer for computer groups than for face-to-face groups, perhaps as a result of the inability of computer group leaders to influence other members who strongly maintain different positions (Hiltz, 1978; Hiltz \& Turoff, 1978; Johansen, 1977, Murrell, 1984). Other researchers have suggested that an absence of the usual visual clues in computer communication may encourage a greater emphasis on communication content, rather than on its social context (Deutsch \& Gerard, 1955).

Murrell (1984) studied the impact of computer-based communication on the group decision-making performance of adults. She concluded that computer conferencing did not modify the characteristic group decrement in brainstorming performance observed in groups interacting face-to-face (in fact, she found, groups interacting through electronic communications systems tended to generate fewer ideas than the same number of people working individually). When groups needed to organize for decision making, however, the computer groups produced decisions that were judged superior to the average initial individual decisions. 
Many standardized psychological tests and interview inventories have recently been adapted for computer administration. Research comparing the use of computer and paper-and-pencil interview techniques with high school students found that although the two methods appeared to collect similar data, the computer interview seemed to evoke more positive subject evaluations and more complete information (Erdman, Klein, \& Greist, 1983). Canoune and Leyhe (1985) investigated the possibility that the direct client-computer interaction may cause the client to respond quite differently to the computer interview or testing than to a human interview or assessment procedure. They concluded that a subject's degree of defensiveness or anxiety probably does depend upon the type of interview, and that subjects' responses in the computerinterview setting were less biased by a need to conform, to be benevolent, or to receive recognition.

In brief, computer-mediated communication among adults does seem to promote different patterns of communication, diminish some forms of group leadership dominance, encourage lengthier interactions, and, possibly, reduce the level of anxiety experienced in the communication process. At this time, however, relatively little is known about the degree to which these findings would apply to either a normal or a clinical adolescent population.

\section{THE STUDY}

Electronic communication has been described as one of the more powerful aspects of computer technology (Vallee, 1982). In an attempt to assess the extent of some of its possible social and psychological effects upon youth, the exploratory study reported here compared the computer-mediated communications of 18 emotionally disturbed adolescents with transcripts of their face-to-face communications in small groups.

The comparison was based on the application of content analysis to each type of text, using the Harvard $I V$ Psychosociological Dictionary as a content analysis tool. The Harvard IV Dictionary contains a set of 104 primary and secondary consensually validated thematic categories. Its categories refer to a number of general classifications, including concrete objects, the natural world, psychological states, behavioral processes, social institutions, interpersonal concerns, object-relations stance, ascribed role status, and expressive styles (Dunphy, Bullard, \& Crossing, 1973; Rochester, 1980; Stone, Dunphy, Smith, \& Ogilvie, 1966).

In particular, the present study attempted to specify the differences between computer-mediated and face-to-face communications among the subjects in seven areas: certain structural aspects of the communications, the expression of emotions or feelings, the degree of interpersonal interest, major institutional concerns, object-relations stance, role or status concerns, and expressive styles.

\section{METHOD}

\section{Subjects}

The study was conducted at a special-education day school located in an inner-city neighborhood of a large midwestern urban center. A total of 18 adolescents were included in the study. All were full-time students who had been psychiatrically evaluated and referred to this school by their local public school special-education diagnostic centers. The group consisted of 11 males and 7 females; their ages ranged from 13 to 20 years, with an average age of 16 years. Nine (50\%) were from families whose major source of income was public assistance. Nine (50\%) were white, $6(33 \%)$ were black, and $3(17 \%)$ were Hispanic. The adolescents presented a wide range of psychopathology. Four (22\%) had been diagnosed as schizophrenic, $6(34 \%)$ had some form of affective or mood disorder, 7 (39\%) had conduct disorders, and 1 (5\%) had a developmental disorder.

\section{Procedure}

System usage. The students were involved in an 11month-long computer project, which offered them computer-aided instruction (CAI) in basic academic skills and access to an electronic group communications file. Each student was scheduled to work with the system at least twice a week, for 30 min each session. During these periods, students voluntarily used the group notes file to communicate with each other. They were informed that no one outside the group, except the researchers, had access to the file and that there were no constraints regarding language, grammar, or subject matter. One of the researchers functioned as the file administrator, but the role was limited to technical matters and to the facilitation of system use.

Data analysis. All student notes and responses in the group's computer-mediated communications file were automatically stored and printed out at the end of the project for use as one set of data. In addition, during the course of the project all participants were tape-recorded in one 5-min session of group "free speech," in 3-member groups. As in the computer-mediated mode, group members were instructed that there were no constraints upon their discussions in terms of subject matter or language use. The interviewer intervened only when necessary to encourage the students to continue speaking. The audiotapes were then transcribed to typescripts, providing the second set of data for study and comparison. These freespeech procedures, and the size of the resulting face-toface word sample, were comparable to those reported in other content analysis studies of face-to-face language production (Maher, McKean, \& McLaughlin, 1966; Oxman, Rosenberg, \& Tucker, 1982; Rochester, 1980; Rosenberg \& Tucker, 1979; Tucker \& Rosenberg, 1975).

Each set of data, the record of computer communication $(5,629$ words) and the typescript of the group free- 
speech sample $(4,595$ words), was analyzed by both qualitative and exploratory quantitative content analysis, using the Harvard IV Dictionary.

\section{RESULTS}

\section{Structural Language Differences}

Type-token ratio. The type-token ratio (TTR) is a ratio obtained by dividing the number of different words (types) by the total number of words (tokens) occurring in the sample. It gives a measure of the range of different words used in a text. Previous research has indicated that lower TTRs are associated with more pathological and disorganized subjects (Fairbanks, 1944; Lorenz \& Cobb, 1954; Mann, 1944; Maher et al., 1966; Whitehorn \& Zipf, 1943). This may reflect either an impoverished and repetitive vocabulary or a reliance upon unconventional, overly idiosyncratic language. Use of the Harvard IV Dictionary made possible an analogous comparison. In this study, the ratio computed was that of the total number of different tags (thematic categories) to the total number of words tagged in each sample. Rounded to 100ths, the TTR ratios for computer-mediated and face-to-face texts were identical (.03).

"Leftovers" (words that received no first- or secondorder tag) were also examined in order to determine whether a higher percentage of unassignable or less common words were being employed in one of the two samples. Results showed that the percentage of words that could not be tagged was virtually identical for the two samples. Thirty-five percent of the words in the computer sample could not be tagged, and $34 \%$ of the face-to-face sample received no thematic definition. Of the leftovers, $13 \%$ in the computer sample could be classified as proper names, whereas slightly fewer $(10 \%)$ of the words in the face-to-face sample could be classified in this category. These findings suggest that computer-mediated and faceto-face communications did not differ substantially in the range of different words used.

Egocentricity index. A popular structural language comparison in content analyses has been the degree of egocentricity, measured by the frequency of self-referring pronouns (Maher et al., 1966). Earlier studies found that normal subjects made more references to the self than did disorganized or schizophrenic subjects (Lorenz \& Cobb, 1954; Mann, 1944). The normals' more frequent selfreferences seemed to be due to a greater interest in themselves and their own lives. In the present study, an index score for self-referring pronouns in each sample was derived by computing the frequency of words in the SELF category divided by the total number of words in the sample. An index ratio between the index scores of the two samples was then calculated. Computer-mediated communication was somewhat more egocentric (index score $=71.1$; index ratio $=1.1$ ) than was face-to-face communication (index score $=63.55$; index ratio $=.9$ ).

Distress-relief quotient. The distress-relief quotient (DRQ; Dollard \& Mowrer, 1947) can be used to mea- sure differences in levels of tension or anxiety in the faceto-face and computer-mediated interpersonal contacts. The DRQ is obtained by computing the ratio of "distress" categories or themes to "relief" themes, as defined by the Harvard Dictionary (see Maher et al., 1966). Two measures were made of the DRQ, using the feeling (emotion) categories. One measure consisted of the frequency of words in the NEED and PAIN categories, divided by the sum of the frequencies in the NEED, PAIN, and PLEASURE categories. The second ratio consisted of the frequency of words in the AROUSAL category, divided by the sum of the frequencies in the AROUSAL and PLEASURE categories. The results of both these measures are shown in Table 1 . It should be noted that by either index, the computer-mediated communication has a lower DRQ, indicating less stress or tension underlying that mode of group discussion. This finding seems to be in agreement with conclusions reached by Canoune and Leyhe (1985).

\section{Thematic Differences}

Thematic tag (category) index scores proportional to sample length were derived by dividing the frequencies of the category assignments by the total number of words in each sample and multiplying the quotient by 1,000 . Index ratios between the two communication modes were then computed. The category differences between the two communication modes are summarized in Table 2. This table presents only the first-order thematic tags that met two levels of difference: (1) the index ratio between the two samples, rounded to 10 ths, equaled or exceeded 1.5, and (2) at least one of the two samples had produced the tag a minimum of 20 times. (Index ratios that met these criteria will be referred to as "high index ratios.") This eliminated all index ratios that were high, but were dependent upon very low absolute raw frequencies.

Table 2 illustrates a number of general thematic differences between the computer-mediated and face-to-face communication modes. First, the computer sample made more frequent use of words referring to psychological states and disclosing feelings and emotions (high index ratios for PAIN, PLEASURE, KNOW, AROUSAL, and NEED), whereas the face-to-face sample stressed only one theme in this area (high index ratio for VICE). Second, the computer-mediated communication was more concerned with a range of interpersonal dynamics (high index

Table 1

A Comparison of Tension Levels in Computer-Mediated (Computer) and Face-to-Face (FTF) Communications Among Disturbed Adolescents $(N=18)$

\begin{tabular}{lcccr}
\hline \multicolumn{1}{c}{ Thematic Categories } & Computer $F$ & Index & FTF $F$ & Index \\
\hline Need + Pain & 88 & 15.63 & 36 & 7.83 \\
Need + Pain + Pleasure & 122 & 21.67 & 44 & 9.57 \\
DRQ (1) & .72 & \multicolumn{4}{c}{.82} \\
Arousal & 83 & 14.75 & 42 & \\
Arousal + Pleasure & 117 & 20.79 & 50 & 10.88 \\
DRQ (2) & .71 & \multicolumn{4}{c}{.84} \\
\hline
\end{tabular}

Note-DRQ = distress-relief quotient (Dollard \& Mowrer, 1947). 
Table 2

A Comparison of First-Order Thematic Tags in Computer-Mediated and Face-to-Face Communications Among Disturbed Adolescents $(N=18)$

\begin{tabular}{|c|c|c|c|}
\hline \multicolumn{2}{|c|}{ Computer-Mediated } & \multicolumn{2}{|l|}{ Face-to-Face } \\
\hline Tag & $\begin{array}{l}\text { Index } \\
\text { Ratio }\end{array}$ & Tag & $\begin{array}{l}\text { Index } \\
\text { Ratio } \\
\end{array}$ \\
\hline Concrete Objects & & Concrete Objects & \\
\hline Human, Collective & 2.3 & Tool & 2.0 \\
\hline Psychological States & & Natural Object & 1.9 \\
\hline Pain & 4.9 & Impersonal Pronoun & 1.8 \\
\hline Pleasure & 3.5 & Relative Pronoun, & 1.6 \\
\hline Know & 1.8 & Impersonal & \\
\hline Arousal & 1.6 & Psychological States & \\
\hline Need & 1.6 & Vice & 1.6 \\
\hline Behavior & & Behavior & \\
\hline Interrelate & 2.9 & Say & 1.7 \\
\hline Communication Form & 1.6 & Fetch & 1.7 \\
\hline Ritual & 1.6 & Natural World & \\
\hline Natural World & & Vary & 1.6 \\
\hline Persist & 2.3 & Space & 1.6 \\
\hline Quality & 1.8 & Natural Processes & 1.5 \\
\hline
\end{tabular}

ratios for HUMAN, COLLECTIVE, INTERRELATE, and RITUAL), whereas the social concerns expressed in the face-to-face discussions were more limited to acquisitive desires (high index ratio for FETCH). Finally, computer-mediated communication tended to emphasize a mutual and transactional quality (high index ratio for COMMUNICATIONS FORM), whereas the face-to-face discussions were typified by a more direct, unilateral form of communication (high index ratio for SAY).

Institutional concerns. Table 3 compares the references made to different institutional categories in the two samples, indicating the particular social institutions of major concern in each type of communication. In terms of raw frequency, both samples tended to show a greater interest in three types of institutions: academic, economic, and expressive (indicated by words referring to selfexpression, including the artistic occupations and instruments). The computer sample made slightly more references to political themes than did the face-to-face sample. The major difference shown in Table 3 , however, is the high index ratio for ECONOMIC in the face-toface sample. This seems to be in line with the face-toface emphasis upon acquisitiveness previously noted in Table 2 (high index ratio for FETCH).

Object-relations stance. The Osgood semantics categories, shown in Table 4, provide measures related to object-relations stance. They reflect the premise that when human beings perceive themselves and others, the most relevant discriminations are made in a space defined by three dimensions: evaluative factors (POSITIVE, NEGATIVE), potency factors (STRONG, WEAK), and activity factors (ACTIVE, PASSIVE).

Table 4 indicates that for five of the six factors related to object relations, the index ratios for the computer mode were somewhat higher than those for the face-to-face communication. Computer-mediated communication showed a noticeable emphasis on words indicating a positive evaluative stance toward the self and others (high index ratio for POSITIVE).

Role interests. The status categories shown in Table 5 indicate the strength of different role interests reflected in each type of communication in terms of family, race, gender, and adult/nonadult dimensions.

As Table 5 indicates, the computer sample made more frequent reference to the female role (high index ratio for FEMALE). It was also more concerned with issues related to a nonadult role (high index ratio for NON-ADULT). The face-to-face discussions, on the other hand, were oriented more toward the male role and family concerns (high index ratios for MALE and KIN). It is interesting to note that in this multiethnic group, racial considerations were insignificant in both communication modes.

Expressive styles. Table 6 compares the use of three general communicative styles in the computer-mediated and face-to-face communications. The categories measure tendencies to overstate, understate, or negate in language use. OVERSTATE refers to the use of words that tend to enlarge and exaggerate the content of the communication; UNDERSTATE words tend to modify, limit, or deemphasize the content; NEGATE includes any word that reverses the meaning of a word, phrase, or sentence. Both OVERSTATE and UNDERSTATE have been used as indicators of defensiveness in communication; NEGATE can be viewed as an indication of negativity and opposition.

Table 3

A Comparison of References to Social Institutions in Computer-Mediated and Face-to-Face Communications Among Disturbed Adolescents $(N=18)$

\begin{tabular}{|c|c|c|c|c|c|c|}
\hline \multirow[b]{2}{*}{$\begin{array}{c}\text { Category } \\
\text { (Tag) }\end{array}$} & \multicolumn{3}{|c|}{ Computer-Mediated } & \multicolumn{3}{|c|}{ Face-to-Face } \\
\hline & $F$ & $\begin{array}{l}\text { Index } \\
\text { Score }\end{array}$ & $\begin{array}{l}\text { Index } \\
\text { Ratio }\end{array}$ & $F$ & $\begin{array}{l}\text { Index } \\
\text { Score }\end{array}$ & $\begin{array}{l}\text { Index } \\
\text { Ratio }\end{array}$ \\
\hline \multicolumn{7}{|l|}{ Institutions } \\
\hline Political & 28 & 4.97 & 1.34 & 17 & 3.70 & .75 \\
\hline Expressive & 81 & 14.39 & 1.18 & 56 & 12.10 & .85 \\
\hline Academic & 52 & 9.24 & .92 & 46 & 10.01 & 1.08 \\
\hline Religious & 4 & .71 & .82 & 4 & .87 & 1.23 \\
\hline Economic & 61 & 10.84 & .66 & 75 & 16.32 & 1.51 \\
\hline Military & 2 & .36 & .24 & 7 & 1.52 & 4.22 \\
\hline Legal & 1 & .18 & .21 & 4 & .87 & 4.83 \\
\hline
\end{tabular}

Table 4

A Comparison of References to the Osgood Semantics Categories in Computer-Mediated and Face-to-Face Communications Among Disturbed Adolescents $(\mathrm{N}=18)$

\begin{tabular}{|c|c|c|c|c|c|c|}
\hline \multirow[b]{2}{*}{ Category (Tag) } & \multicolumn{3}{|c|}{ Computer-Mediated } & \multicolumn{3}{|c|}{ Face-to-Face } \\
\hline & $F$ & $\begin{array}{l}\text { Index } \\
\text { Score } \\
\end{array}$ & $\begin{array}{l}\text { Index } \\
\text { Ratio } \\
\end{array}$ & $F$ & $\begin{array}{l}\text { Index } \\
\text { Score } \\
\end{array}$ & $\begin{array}{l}\text { Index } \\
\text { Ratio }\end{array}$ \\
\hline \multicolumn{7}{|l|}{ Osgood Semantics } \\
\hline Positive & 364 & 64.67 & 1.47 & 202 & 43.96 & .68 \\
\hline Passive & 302 & 53. & 1. & 179 & 38.96 & .73 \\
\hline Negative & 109 & 19.36 & 1.29 & 69 & 15.02 & .78 \\
\hline Weak & 83 & 14.75 & 1.19 & 57 & 12.41 & .84 \\
\hline Strong & 250 & 44.41 & 1.10 & 186 & 40.48 & .91 \\
\hline Active & 516 & 91.67 & .98 & 430 & 93.58 & 1.02 \\
\hline
\end{tabular}


Table 5

A Comparison of References to Role Status in Computer-Mediated and Face-to-Face Communications Among

Disturbed Adolescents $(N=18)$

\begin{tabular}{|c|c|c|c|c|c|c|}
\hline \multirow[b]{2}{*}{$\begin{array}{l}\text { Category } \\
\text { (Tag) }\end{array}$} & \multicolumn{3}{|c|}{ Computer-Mediated } & \multicolumn{3}{|c|}{ Face-to-Face } \\
\hline & $F$ & $\begin{array}{l}\text { Index } \\
\text { Score }\end{array}$ & $\begin{array}{l}\text { Index } \\
\text { Ratio }\end{array}$ & $F$ & $\begin{array}{l}\text { Index } \\
\text { Score }\end{array}$ & $\begin{array}{l}\text { Index } \\
\text { Ratio }\end{array}$ \\
\hline \multicolumn{7}{|l|}{ Status } \\
\hline Nonadult & 41 & 7.28 & 3.05 & 11 & 2.39 & .33 \\
\hline Female & 90 & 15.99 & 1.56 & 47 & 10.23 & .64 \\
\hline Kin & 18 & 3.20 & .59 & 25 & 5.44 & 1.70 \\
\hline Male & 98 & 17.41 & .57 & 143 & 31.12 & 1.79 \\
\hline Race & 1 & .18 & - & 0 & .00 & - \\
\hline
\end{tabular}

As Table 6 shows, the computer-mediated communication had a slightly higher index ratio for UNDERSTATE, suggesting a somewhat more defensive (hesitant and tentative) language style. The more important observation, however, is that the face-to-face communication had a high index ratio for NEGATE. This could well associate with that mode's high index ratio for words in the negative psychological category of VICE (see Table 1), which suggests a negative evaluation process and preoccupation with vice and social misfortunes.

\section{DISCUSSION}

\section{Summary of Findings}

Some observers have voiced fears that the use of computers by youth will lead to affective withdrawal, foster a mechanistic way of thinking, and create a subculture of sociopaths. The findings of this exploratory study of one powerful aspect of computer technology, electronic communication, cast some doubt upon those concerns. In fact, this study suggests that computer-mediated communication may represent a new resource for eliciting emotionally rich, relationship-oriented verbal interaction among emotionally disturbed adolescents.

1. With regard to structural language characteristics, the results showed that word usage in the computer mode was neither more impoverished nor less conventional than that in the face-to-face mode. Computer communication was slightly more self-referent; it also appeared to be accompanied by a lower level of experienced tension or stress.

2. In terms of emotions, the findings indicated that the computer-mediated communication was more consistently expressive of feelings and was also more frequently con-

Table 6

A Comparison of References to Expressive Style in Computer-Mediated and Face-to-Face Communications Among Disturbed Adolescents $(N=18)$

\begin{tabular}{|c|c|c|c|c|c|c|}
\hline \multirow[b]{2}{*}{$\begin{array}{c}\text { Category } \\
\text { (Tag) }\end{array}$} & \multicolumn{3}{|c|}{ Computer-Mediated } & \multicolumn{3}{|c|}{ Face-to-Face } \\
\hline & $F$ & $\begin{array}{l}\text { Index } \\
\text { Score }\end{array}$ & $\begin{array}{l}\text { Index } \\
\text { Ratio } \\
\end{array}$ & $F$ & $\begin{array}{l}\text { Index } \\
\text { Score }\end{array}$ & $\begin{array}{l}\text { Index } \\
\text { Ratio } \\
\end{array}$ \\
\hline \multicolumn{7}{|l|}{ Style } \\
\hline Understate & 148 & 26.99 & 1.15 & 108 & 23.50 & .87 \\
\hline Overstate & 202 & 35.88 & 1.01 & 163 & 35.47 & .99 \\
\hline Negate & 88 & 15.63 & .54 & 132 & 28.73 & 1.84 \\
\hline
\end{tabular}

cerned with interpersonal relationships. This interest in relationships was reflected in other, more particular communication characteristics. For instance, the computer communication tended to be more transactional than communication in the face-to-face mode, which was unilateral and frequently negative.

3. Measures of object-relations stance showed that the face-to-face communication had lower index ratios than computer communication for five of the six objectrelations dimensions. The computer mode was high for a positive evaluative stance toward the self and others.

4. There were similarities between the two modes in the area of institutional interests and concerns. Both types of communication made frequent use of words associated with academic, economic, and expressive social contexts. The face-to-face communication, however, was especially high for financial matters, which may be associated with its generally acquisitive social preoccupation.

5 . With regard to role perceptions, the computer mode was high for an interest in female issues, in opposition to the face-to-face tendency to show a male-dominated orientation. The adolescents' computer communications also tended to be more adaptive on the adult/nonadult dimension, indicating a perhaps more realistic identification with nonadult interests and issues.

In summary, the findings indicated a number of observable differences between the computer-mediated and faceto-face communications among this group of adolescents. Computer communication was slightly more egocentric and was accompanied by a lower level of tension. It was more expressive of feelings and made more frequent reference to interpersonal issues. Furthermore, the computermediated language reflected a more positive objectrelations stance, was less negative in expressive style, and appeared to diminish certain traditional gender differences in group communication.

\section{Underlying Factors}

The main intent of this exploratory psychosocial content analysis was simply to describe and compare the computer-mediated and face-to-face communications of a group of disturbed adolescents. Nevertheless, it may be useful to speculate about some of the possible underlying factors that could have influenced the reported language differences. In a very general way, previous writers have suggested that positive user-machine interactions such as these may derive from a protective sense of anonymity promoted by the computer (Toles, 1984), or that they may relate to feelings of security engendered by experiencing the computer as a "transitional object" (Turkle, 1984). More specifically, however, the research results may also have been influenced by such factors as the unique computer system features or the users' socioeconomic characteristics.

Impact of system features. Research on CAI has shown that rapid response time can stimulate interest, whereas slow system response time and downtime can negatively affect user attitudes and motivation, especially 
when there is great variability in response time (Carbonell, Elkind, \& Nickerson, 1968). Murrell (1984) reached similar conclusions with regard to computer conferencing. The rate of display and screen display size have also been shown to affect user performance (Dennis, 1979). The technological features of the Plato system, which was employed in this study, may well have had a positive influence on the adolescents' attitudes and motivational feelings in the conferencing mode. It had extremely rapid keyresponse times of less than $1 / 8 \mathrm{sec}$. The system's reliability was high, with more than $95 \%$ of scheduled time available to the users. Text was written on screen at a speed of 180 characters per second. Finally, the bulletin-board format group notes-file could be accessed and manipulated with ease.

Effect of users' socioeconomic characteristics. Very few studies have addressed the interaction of demographic or socioeconomic variables with outcomes of either CAI or electronic communication. CAI users with disadvantaged or educationally deficient backgrounds have been studied to a limited extent. Osin (1980) found highly significant learning gains for disadvantaged Israeli students using CAI. Siegel and DiBello (1980) reported that Job Corps participants with deprived backgrounds and poor achievement histories were more likely to achieve learning objectives and report high satisfaction with CAI than in a traditional face-to-face setting. Saracho (1982) reached similar conclusions in a study of CAI with Spanish-speaking migrant children. Accordingly, the disadvantaged and educationally deficient backgrounds of the adolescents in the present study may also have contributed to their positive response in the computer-conferencing mode.

\section{CONCLUSION}

The present study revealed communication factors in the computer setting that suggest that, for disturbed adolescents, the computer might facilitate a greater capacity for participation in therapeutic activities. This increased sense of openness was characterized by a heightened sensitivity to psychological themes, a greater emphasis upon emotional issues, and a tendency to resolve in an adaptive way, rather than with opposition. These observations further suggest that one rewarding avenue of future research might be the development and evaluation of specialized techniques for using computers with clinical populations of children and adolescents in specialeducation and therapeutic contexts.

\section{REFERENCES}

Canoune, H. L., Leyhe, E. W. (1985). Human versus computer interviewing. Joumal of Personality Assessment, 49, 103-106.

Carbonell, J. R., Elkind, J. I., a Nickerson, R. S. (1968). On the psychological importance of time in a time-sharing system. Human Factors, 10, 135-142.

DAVY, J. (1984). Mindstorms in the lamplight. Teachers College Record, 85, 631-639.
DeKEN, J. (1982). The electronic cottage. New York: Morrow.

DENNIS, V. E. (1979). The effect of display rate and memory support on correct responses, trials, total instructional time and response latency in a computer-based learning environment. Joumal of ComputerBased Instruction, 6(2), 50-54.

DeUtsch, M., Gerard, H. B. (1955). A study of normative and informational social influences upon individual judgment. Journal of Abnormal \& Social Psychology, 51, 629-636.

DollarD, J., MowRER, O. H. (1947). A method of measuring tension in written documents. Journal of Abnormal \& Social Psychology, 42, 3-32.

Dunphy, D. C., Bullard, C. G., Crossing, E. E. M. (1973). Validation of the General Inquirer Harvard IV Dictionary (Unpublished report). Cambridge, MA: Harvard University, Department of Social Relations.

Erdman, H., KLEIN, M. H., \& Greist, J. H. (1983). The reliability of a computer interview for drug use/abuse information. Behavior Research Methods \& Instrumentation, 15, 66-68.

Evans, D. (1979). The micro millenium. New York: Viking.

FaIrbanks, H. (1944). The quantitative differentiation of samples of spoken language. Psychological Monographs, 56(255), 19-28.

Harvard IV psychosociological dictionary (Unpublished dictionary). (1973). Cambridge, MA: Harvard University, Department of Social Relations.

HiLTz, S. R. (1978). Controlled experiments with computerized conferencing. Bulletin of the American Society for Information Science, 4(5), 11-12.

Hiltz, S. R., \& TURoFF, M. (1978). The network nation: Human communication through computer. Reading, MA: Addison-Wesley.

JoHANSEN, R. (1977). Social evaluations of teleconferencing. Telecommunications Policy, 1, 395-419.

LEPPER, M. F. (1982, August). Microcomputers in education: Motivational and social issues. Paper presented at the 90th annual meeting of the American Psychological Association, Washington, DC.

Lipinski, H. M., Vian, K., Plummer, R., Spang, S., Tydeman, J., \& McNeal, B. (1979). Interactive group modeling and the Hub User's Guide (Report R-44 to R-47). Menlo Park, CA: Institute of the Future.

LoRenz, M., CoBB, S. (1954). Language patterns in psychotic and psychoneurotic subjects. Archives of Neurological Psychiatry, 72, 665-673.

Maher, B. A., McKean, K. O., McLaughuin, B. (1966). Studies in psychotic language. In P. J. Stone, D. C. Dunphy, M. S. Smith, \& D. M. Ogilvie (Eds.), The General Inquirer: A computer approach to content analysis (pp. 469-503). Cambridge, MA, and London: MIT Press.

MANN, M. B. (1944). The quantitative differentiation of samples of written language. Psychological Monographs, 56(255), 41-74.

MURRELL, S. L. (1984). The impact of communicating through computers (Doctoral dissertation, The State University of New York at Stoney Brook, 1983). University Microfilms International, 3058.

OsIN, L. B. (1980). Computer-assisted instruction in arithmetic in Israeli disadvantaged elementary schools. Unpublished manuscript, Centre for Educational Technology, Department of Computers in Instruction, Ramat Aviv, Israel.

Oxman, T. E., Rosenberg, S. D., Tucker, G. J. (1982). The language of paranoia. American Journal of Psychiatry, 139, 275-282.

PAPERT, S. (1980). Mindstorms: Children, computers, and powerful ideas. New York: Basic Books.

Rice, R. (1980). Computer conferencing. In M. Voigt (Ed.), Progress in communication sciences (pp. 215-240). Norwood, NJ: Ablex.

RochesTER, S. (1980). Thought disorder and language use in schizophrenia. In R. W. Reiber (Ed.), Applied psycholinguistics and mental health (pp. 215-240). New York: Plenum Press.

RosenberG, S. D., TUCKer, G. J. (1979). Verbal behavior and schizophrenia, the semantic dimension. Archives of General Psychiarry, 36, 1331-1337.

SARAcho, O. N. (1982). The effects of a computer-assisted instruction program on basic skills achievement and attitudes toward instruction of Spanish-speaking migrant children. American Educational Research Journal, 19, 201-219. 
SARDELLO, R. J. (1984). The technological threat to education. Teachers College Record, 85, 549-558.

SIEGEL, M. A., \& DiBELLo, L. V. (1980). Plato computer-based education for the Job Corps. Urbana: Computer-based Education Research Laboratory, University of Illinois at Urbana-Champaign.

Simpson, B. (1984). Heading for the ha-ha. Teachers College Record, $85,622-630$.

Stone, P. J., DunPhy, D. C., SMTth, M. S., \& OGILVIE, D. M. (1966). The General Inquirer; $A$ computer approach to content analysis. Cambridge, MA, and London: MIT Press.

Strickland, L. H., Guild, P. D., Barefoot, J. C., \& Paterson, S. A. (1978). Teleconferencing and leadership emergence. Human
Relations, 31, 583-596.

Toles, M. (1984). Creating electronic communities: Mass and vernacular technologies for interpersonal communication via computer (Doctoral dissertation, Cornell University, 1983). University Microfilms International, 3058.

Tucker, G. J., \& Rosenberg, S. D. (1975). Computer content analysis of schizophrenic speech: A preliminary report. American Journal of Psychiatry, 132, 611-616.

TURKLE, S. (1984). The second self. New York: Simon \& Schuster. VALIEE, J. (1982). The network revolution. Berkeley, CA: And/Or Press. WhITEHORN, J., \& ZiPF, G. (1943). Schizophrenic language. Archives of Neurological Psychiatry, 49, 831-851. 